\title{
REIFICAÇÃO E QUESTÃO AMBIENTAL: CONTRIBUIÇÕES DE KARL MARX PARA A AGENDA DE UMA EDUCAÇÃO AMBIENTAL CRÍTICA
}

\author{
Everaldo Nunes de Farias Filho ${ }^{1}$ \\ Louise Claudino Maciel ${ }^{2}$
}

\begin{abstract}
RESUMO
Este artigo discute alguns conceitos e ideias de Karl Marx que podem contribuir na agenda de construção de uma Educação Ambiental ancorada em uma visão holística e crítica da relação sociedade e natureza. Dessa forma, analisamos o desenvolvimento do conceito de reificação como chave da crítica marxista à sociedade capitalista que se desenvolve em torno dos conceitos de alienação, de ideologia e de fetichismo da mercadoria, cada qual guardando um momento específico da obra do autor, assim como o diálogo com interlocutores diferentes. Após desenvolver uma abordagem para o conceito de reificação, utilizamos a crítica marxista da consciência reificada para contribuir com o fomento de uma visão holística e não reducionista da questão ambiental, tendo em vista uma Educação Ambiental de cunho crítico e emancipador.
\end{abstract}

Palavras-chave: Karl Marx; reificação; alienação; educação ambiental.

\section{REIFICATION AND ENVIRONMENTAL QUESTION: KARL MARX'S CONTRIBUTIONS TO THE AGENDA FOR A CRITICAL ENVIRONMENTAL EDUCATION}

\begin{abstract}
This article discusses some concepts and ideas of Karl Marx that can contribute in the construction agenda of an Environmental Education anchored in a holistic and critical view of the relation society and nature. In this way, we analyze the development of the concept of reification as the key to Marxist critique of capitalist society that develops around the concepts of alienation, ideology and fetishism of the commodity, each of which keeps a specific moment of the author's work, as well as dialogue with different interlocutors. After developing an approach to the concept of reification, we use the Marxist critique of reified consciousness to contribute to the promotion of a holistic and non-reductionist vision of the environmental issue, in view of a critical and emancipatory Environmental Education.
\end{abstract}

Keywords: Karl Marx; reification, alienation; environmental education.

\footnotetext{
${ }^{1}$ Doutorando em Ensino de Ciências na Universidade Federal Rural de Pernambuco.

${ }^{2}$ Doutora em Sociologia pela Universidade Federal de Pernambuco.
} 


\section{INTRODUÇÃO}

A questão ambiental como problemática atual agrega transtornos de diversas ordens. Hodiernamente, não é possível associar os problemas ambientais às questões relacionadas apenas com o meio natural. Ao contrário, a problemática ambiental gera infortúnios de ordem não somente natural, mas também social, política, econômica e cultural. Dessa forma, adversidades graves como aquecimento global, poluição das águas, desmatamentos e queimadas, buracos na camada de ozônio e ameaça à vida da flora e fauna, dividem o espaço com reveses sociais como a má distribuição de alimentos, disseminação de tóxicos sintéticos, exploração do trabalho, desigualdades sociais e problemas de saúde pública.

Esses problemas socioambientais atuais têm raízes históricas e culturais profundas no atual sistema econômico dominante. Para gerar bens e serviços visando o lucro alto e rápido, o sistema capitalista cria uma ideologia de que precisamos consumir para sermos felizes. Dessa forma, tramas são elaboradas e estratégias são postas em prática com o objetivo de nos convencer a utilizar cada vez mais bens de consumo. Dentro da ótica capitalista, os recursos naturais que deveriam ser utilizados por todos os indivíduos de forma igualitária, são vistos apenas como matérias-primas para a produção de artefatos e serviços. Nesta esteira, florestas são desmatadas, mananciais são contaminados, reservas minerais são exploradas à exaustão objetivando obter insumos para serem levados às fábricas e indústrias. Com isso, populações de pessoas que vivem nesses locais degradados são obrigadas a sair perdendo o ambiente em que convivem.

Apesar de os problemas ambientais estarem intrinsecamente associados às contradições do sistema capitalista, desde a publicação do relatório "Limites do Crescimento", na década de 1970, não paramos de observar o surgimento de propostas marcadas pelos vieses tecnicistas e individualistas para o enfrentamento desses problemas. Para o evangelho da ecoeficiência, tal como Alier (2007) nomeia uma importante corrente do ambientalismo moderno, o crescimento econômico pode se dar perfeitamente 
aliado a uma "boa" utilização dos recursos naturais. Tal modernização ecológica depende de que se aposte em duas vias principais de ação: uma via econômica, com ecoimpostos e mercados de licenças de emissões, e uma via tecnológica, com medidas voltadas para economia de energia e matérias primas.

Enquanto os vieses economicista e tecnicista proliferam no âmbito da produção, o viés individualista ganha espaço no enfrentamento dos problemas ambientais no âmbito do consumo. Assim, produzem-se soluções do tipo consumo verde (PORTILHO, 2005) como saídas individualizantes que, longe de resolver os problemas ambientais, se convertem em mais uma fonte para o lucro capitalista, visto que grupos sociais com alto capital econômico e cultural (BOURDIEU, 2003) passam a figurar como nichos privilegiados do mercado "verde".

Em um momento em que esses discursos, que partilham de uma visão reducionista da questão ambiental, ganham adeptos e espaços nos debates e nas ações privadas e públicas em torno da sustentabilidade, um retorno às ideias de Karl Marx mostra-se muito importante na agenda de construção de uma Educação Ambiental, ancorada em uma visão holística e crítica da relação Sociedade e Natureza. Tal visão exige, dentre outros aspectos: 1) a contextualização histórico-político-social em que se estabeleceu um padrão de civilização criado para satisfazer as necessidades de uma sociedade capitalista; 2) a compreensão da relação Sociedade e Natureza permeada por conflitos e contradições derivadas da organização das relações de produção no capitalismo; 3) o entendimento da questão ambiental como parte de um campo de lutas, no qual se trava uma constante batalha para definir e hierarquizar os problemas ambientais, bem como para legitimar os modos mais adequados de confrontá-los e, por fim, 4) uma crítica às saídas reducionistas e individualizantes que têm emergido no campo ambiental para o enfrentamento da crise ecológica.

A fim de construir essa visão holística da questão ambiental, é preciso confrontar o problema antigo, denunciado por Karl Marx e por seus seguidores, 
da reificação da consciência sob o capitalismo, pois ele impede uma visão abrangente dos problemas sociais e, hodiernamente, fomenta uma consciência fragmentada da questão ambiental.

Com esse objetivo, na primeira seção, este artigo analisa 0 desenvolvimento desse conceito chave da crítica marxista à sociedade capitalista. Se sua grafia coube a um dos mais importantes pensadores do marxismo ocidental (ANDERSON, 2004), György Lukács, o seu núcleo argumentativo já se encontra em Karl Marx. Ele desenvolve-se em torno dos conceitos de alienação, de ideologia e de fetichismo da mercadoria, cada qual guardando um momento específico da obra do autor, assim como o diálogo com interlocutores diferentes. Após desenvolver uma abordagem para 0 conceito de reificação, utilizamos a crítica marxista da consciência reificada, para, na segunda seção deste artigo, contribuir com o fomento de uma visão holística e não reducionista da questão ambiental, tendo em vista uma Educação Ambiental de cunho crítico e emancipador.

\section{DA ALIENAÇÃO À REIFICAÇÃO: A FRAGMENTAÇÃO DA REALIDADE SOCIAL SOB O CAPITALISMO}

É possível amparar-se na obra de Karl Marx para lidar com os problemas ambientais do nosso tempo? Para Buttel (1992), Marx, assim como Max Weber e Émile Durkheim, teria deixado muito pouca contribuição nessa direção. Para legitimar as Ciências Sociais no campo científico, esses autores necessitaram combater a tese de que as sociedades eram determinadas por forças da natureza. Assim, sustentaram uma posição contrária aos determinismos geográficos e biológicos e às explicações que utilizassem dados biológicos e ambientais para compreender as mudanças sociais. Além disso, outro fator explicaria o déficit ecológico dos pensadores clássicos das Ciências Sociais. Eles refletiram em um contexto marcado pela ideologia do progresso e da modernização. Ressaltavam, assim, os benefícios da inovação tecnológica e do desenvolvimento econômico. Desse modo, a crítica feroz de Marx às desigualdades sociais geradas pelo modo de produção capitalista dividia lugar com a crença no potencial libertador do avanço das forças produtivas. 
Mesmo não tendo a questão ambiental como central a sua teorização, Karl Marx não deixou de inspirar estudos que lidam com essa problemática. De maneira geral, a atual crise socioambiental relaciona-se com a histórica luta de classes existentes no capitalismo evidenciada nos escritos de Karl Marx e seus seguidores. Na visão marxista da relação sociedade e ambiente, uma pequena parcela da população desfruta dos benefícios da superexploração dos recursos naturais enquanto a maioria dos seres humanos trabalha para sustentar esse sistema econômico e arcar com os ônus trazidos pela degradação do meio ambiente juntamente com as demais mazelas socioambientais decorrentes do capitalismo. Assim, estudos sobre injustiça ambiental (ALIER, 2007) e conflitos ambientais (ZHOURI; LASCHEFSKI, 2010) ancoram-se profundamente na concepção do desenvolvimento histórico como um desdobrar do conflito entre as classes sociais, um dos pilares do materialismo histórico (MARX, 2008). Retornaremos a esses estudos na segunda seção deste artigo. Por hora, exploraremos o conceito reificação na perspectiva de Marx e de seus seguidores, pois nos permite compreender a dificuldade de estabelecer uma visão holísticae crítica dos problemas ambientais, conduzindo ao reducionismo no tratamento desses problemas.

O conceito reificação foi desenvolvido por Lukács no livro História e Consciência de Classe. No entanto, o núcleo argumentativo do conceito já se encontra na noção de alienação de Karl Marx. A concepção do homem como um ser que se autoproduz pelo trabalho é um dos fundamentos essenciais da filosofia marxista. Desse modo, Marx (2008) estabelece, na Ideologia Alemã, que o primeiro fato histórico é a produção dos meios que permitam aos homens a satisfação de suas necessidades vitais, ou seja, a produção de uma vida material. A satisfação das necessidades existentes leva à produção de outras necessidades. Ademais, a produção da vida surge como dupla relação: uma relação natural, na qual os seres humanos, em relação com a natureza, produzem valores de uso, e uma relação social, que envolve a cooperação de vários indivíduos e que pode assumir diferentes condições, modos e finalidades. 
Como afirma Mézáros (2006), Marx considera o trabalho tanto em sua acepção geral, ou seja, como atividade produtiva e determinação ontológica fundamental do ser humano, como em sua acepção particular, isto é, o trabalho na forma da divisão do trabalho capitalista. É somente nessa última forma, o trabalho estruturado em moldes capitalistas, que a atividade produtiva se converte em base de toda a alienação. No capitalismo, o trabalho converte-se em alienação, pois o ser humano confronta-se com o produto do seu trabalho como algo que Ihe é estranho e que o domina. Para Marx (2004, p. 112):

\begin{abstract}
A alienação do trabalhador no seu produto significa não só que o trabalho se transforma em objeto, assume uma existência externa, mas que existe independentemente, fora dele e a ele estranho, e se torna um poder autônomo em oposição a ele; que a vida que deu ao objeto se torna uma força hostil e antagônica.
\end{abstract}

Quando o ser humano deixou de ser o sujeito do processo de trabalho, isto é, de determinar as suas condições (tais como o tipo de atividade, hora, local), o trabalho ficou reduzido à meio de sobrevivência. Em tal situação, a própria especificidade do mundo humano com relação ao mundo animal foi eliminada, a de produzir para além da garantia da sua sobrevivência e fazer da atividade vital o objeto da vontade e da consciência (MARX, 2004). No capitalismo, Marx identifica mediações de segunda ordem que se interpõem entre o ser humano e o seu trabalho e fomentam a alienação. Tais mediações correspondem à propriedade privada, à troca e à divisão do trabalho no capitalismo (MÉZÁROS, 2006).

O termo alienação, recorrente nos Manuscritos Econômicos Filosóficos, desaparece da obra posterior de Marx, até mesmo em um texto considerado de transição, como A Ideologia Alemã. Segundo Ricoeur (1997, p.125), "isso ocorre porque o termo está muito atrelado aos filósofos idealistas, principal alvo da crítica de Marx nessa obra". Marx critica tais filósofos que concebem a consciência como o motor da história. Para Marx, a história não é fruto do espírito absoluto, mas fruto do trabalho humano. É o trabalho que condiciona o desenvolvimento da vida social. Se os seres humanos possuem consciência, não se trata de uma consciência "pura", mas de um produto social, ou seja, de uma consciência entrelaçada com as condições materiais de existência dos 
homens. Por que, então, a consciência surge para os filósofos alemães como a força motriz da história? Marx destaca o fator da divisão social do trabalho, entre material e espiritual, para explicar esse processo de inversão na consciência dos filósofos. Para ele, com essa divisão, é dada à consciência a possibilidade de efetivamente imaginar ser algo distinto, "desde então a consciência está em condições de emancipar-se do mundo e entregar-se a criação da teoria, da teologia, da filosofia e da moral, puras, etc. "puras'” (MARX, 2008, p. 58).

Se nesse momento da sua obra, Marx abandona o termo alienação por sua relação com a filosofia do idealismo, o núcleo desse conceito permanece em A Ideologia Alemã:

Essa fixação da atividade social, essa consolidação de nosso próprio produto em um poder objetivo superior a nó mesmos, além do nosso controle, em contradição com as nossas expectativas e que reduz a nada nossos cálculos, é um dos momentos principais do desenvolvimento histórico que tivemos até aqui (MARX, 2008, p. 60).

O mesmo pode-se dizer em relação à obra $O$ Capital, na qual o conceito de alienação renova-se em uma interlocução crítica com os economistas políticos. Como afirma Ruy Fausto (1987, p. 48), nessa obra, Marx trata de explicar como, no capitalismo, o conjunto da classe operária "aliena o seu produto" constantemente. Ele desvela no princípio da troca de equivalentes, que fundamenta a ideologia desse modo de produção, uma apropriação sem equivalente pelo capitalista, por meio da análise do modo de reprodução do capital como um movimento contínuo. Como movimento descontínuo, cada volta do capital figura como independente da que the antecede e da que the procede e o ato da troca é representado pelo encontro fortuito de dois agentes no mercado. Já como movimento contínuo, o caráter contingente do encontro entre o operário e o capitalista e a ideia de uma liberdade de contrato tornamse aparências, pois esses agentes são recriados e reunidos pelo próprio movimento do capital que ao reproduzir o operário enquanto operário o obriga a vender sua força de trabalho. A imagem de uma troca de equivalentes também é desvelada como falsa, pois se demonstra que o capitalismo baseiase em "valor extorquido sem equivalente" da classe operária. $O$ que 0 
capitalista transfere para o trabalhador em forma de salário é parte da riqueza produzida pela classe operária que só pode receber esse valor ao criar um novo produto. De acordo com Ruy Fausto (1987, p. 48):

\begin{abstract}
Essa mudança de perspectiva que representa na realidade uma mudança de sentido, objetiva, do processo, constitui o que Marx chama de interversão da lei da apropriação ou da propriedade, interversão cujos dois momentos poderiam ser resumidos da seguinte maneira: uma volta do capital ou cada volta obedece à lei de apropriação ou de propriedade das economias mercantis, lei segundo a qual a apropriação dos produtos se faz pela troca de equivalentes e depende, em última instância, do trabalho próprio. Mas a repetição das voltas do capital [...] interverte essa lei na lei de apropriação capitalista, uma apropriação sem equivalente do trabalho alheio.
\end{abstract}

Percebe-se que, nesse momento da sua obra, Marx confere um novo patamar para a sua crítica da ideologia. O problema da ideologia não é mais uma questão de consciência que percebe a realidade social erroneamente, tal como estava posto na Ideologia Alemã. Nessa obra, a fim resolver o problema da falsa consciência, bastava inverter a dialética que estava "de cabeça para baixo" no idealismo alemão. Já em O Capital, Marx demonstra que existe uma espécie de dissimulação ou duplicidade embutida nas próprias estruturas econômicas do capitalismo e, por isso, elas se apresentam à consciência de maneira distorcida quanto ao que efetivamente são (EAGLETON, 1997). Desse modo, a inversão, que antes estava na consciência dos filósofos, será identificada na própria realidade social e, por isso, ela está refletida na consciência.

Sob o fetichismo da mercadoria, a relação de troca entre mercadorias surge não como uma relação social, mas como uma relação entre coisas, pois "a igualdade dos trabalhos humanos fica disfarçada sob a forma da igualdade dos produtos do trabalho como valores" (MARX, 1999, p. 84). A mercadoria surge como entidade fantasmagórica por inscrever seu conteúdo eminentemente social sob a forma de uma propriedade inerente ao objeto. Desse modo, as mercadorias não são concebidas como produtos sociais e os produtores são incapazes de perceber que, através da troca dos frutos de seu trabalho no mercado, são eles próprios que estabelecem uma relação social.

Seguindo Marx, Lukács (2003, p. 221) vai demonstrar que, ao se constituir como uma estrutura econômica unificada para toda a sociedade, o 
capitalismo produzirá uma estrutura de consciência unitária para o seu conjunto: a consciência reificada. A reificação é definida pelo aparecimento, na vida social, de processos econômicos como fenômenos autônomos e puramente quantitativos. A diferença entre a reificação das consciências do trabalhador e do empresário capitalista "é uma variação puramente quantitativa, e não uma diferença qualitativa na estrutura da consciência" (LUKÁCS, 2003, p. 219):

O homem não aparece nem, objetivamente, nem em seu comportamento em relação ao processo de trabalho, como o verdadeiro portador desse processo; em vez disso, ele é incorporado como parte mecanizada num sistema mecânico que já encontra pronto e funcionando de modo totalmente independente dele, e a cujas leis ele deve se submeter (LUKÁCS 2003, p. 204).

Lukács (2003) argumenta que é extremamente difícil para o trabalhador se libertar dessa situação, uma vez que a objetivação de sua força de trabalho, em relação ao conjunto de sua personalidade, é percebida como realidade cotidiana, durável e intransponível. Mas, é somente através do autoconhecimento de sua situação, ou seja, de sua condição opressiva na sociedade capitalista, que o trabalhador pode insurgir-se contra ela. Para Lukács, o pensamento é simultaneamente cognitivo e criativo, ou seja, no ato de compreender suas reais condições no sistema capitalista, a classe proletária começa a modelar as formas de consciência que servirão para modificá-las (EAGLETON, 1997, p. 90). Em seu pleno desenvolvimento político, a consciência proletária pode "totalizar" a ordem social, para assim compreender e transformar suas próprias condições (EAGLETON, 1997).

Um dos conceitos mais importantes do chamado Marxismo Ocidental ${ }^{3}$, a problemática da reificação seguirá fundamentando a crítica ao capitalismo em outros importantes pensadores dessa corrente teórica. Não mais presente apenas no mundo do trabalho, o processo de fragmentação da realidade social será visto em todas as esferas da sociedade capitalista, como na própria cultura. Veja-se, nesse sentido, a análise sobre a Indústria Cultural, desenvolvida pelos teóricos da Escola de Frankfurt e que aponta para as novas

\footnotetext{
${ }^{3}$ O termo Marxismo Ocidental é usado aqui no sentido que Perry Anderson (1976) Ihe confere. Características do marxismo ocidental são: a) Abandono da economia política pela Filosofia, b) Realização de trabalhos na Universidade c) Busca dos autores que influenciaram o pensamento de Marx d) Ascensão de trabalhos de cunho epistemológico e) Domínio da estética e de temas da superestrutura.
} 
formas de alienação dos sujeitos na sociedade do capitalismo tardio. Buscando "ocupar os sentidos dos homens da saída da fábrica, à noitinha, até a chegada ao relógio do ponto, na manhã seguinte" (ADORNO; HORKHEIMER, 1985, p. 123), a Indústria Cultural estende os processos que caracterizam o trabalho alienado - mecanização, repetição, ausência de expressão e imaginação - ao tempo livre dos indivíduos. Essa expansão tem como objetivo final a reprodução de padrões de comportamento conformistas e nada questionadores da ordem social vigente.

$\mathrm{Na}$ primeira seção deste artigo, buscamos apresentar uma abordagem sobre o desenvolvimento do conceito de reificação em Marx e nos seus seguidores do Marxismo Ocidental. Para essa corrente teórica, a reificação fragmenta e desloca nossa experiência social, de modo que, sob sua influência, perde-se a capacidade de ver a sociedade como um processo coletivo e a ordem capitalista torna-se menos vulnerável à crítica. Transpondo essa problemática para a questão ambiental, compreendemos porque proliferaram, desde os anos 1970, propostas e soluções que têm em comum uma visão redutora dos problemas ambientais e que deixam intacta a questão sobre o modelo de civilização em que vivemos.

Como afirma Foladori (2001), as análises sobre a crise ambiental costumam enfatizar os limites físicos externos com os quais a sociedade humana se defronta, tais como: mais população do que o contingente populacional que o ecossistema pode suportar; escassez de recursos diante das crescentes necessidades sociais e poluição do meio ambiente em uma velocidade maior do que o ritmo de reciclagem da natureza. Inspirado na obra de Karl Marx, Foladori questiona a redução da questão ambiental a limites externos, pois os problemas ambientais surgem como resultado da organização econômica e social. Essa diretriz deve ser a base da formulação de uma agenda para uma educação ambiental crítica e emancipadora dos sujeitos sociais, como abordaremos na próxima seção deste artigo.

\section{POR UMA VISÃO HOLÍSTICA DA QUESTÃO AMBIENTAL NA EA}


Se, sob o efeito da reificação, perdemos a capacidade de ver os problemas sociais em sua totalidade, a Educação Ambiental (EA) deve visar fomentar nos sujeitos históricos a capacidade de "totalizar" essa ordem fragmentada que concebe os problemas ambientais deslocados de sua origem e deixa intacto o questionamento sobre o modo de civilização em que vivemos. A EA se constitui como um processo educativo de internalização fundado na questão ambiental. Esse processo vai além da conscientização para a preservação do meio ambiente natural e da sensibilização de problemas sociais a partir de práticas comportamentalistas (LOUREIRO, 2005) e fragmentadas (LAYRARGUES, 2011). A concepção de EA deve construir uma visão mais holística da realidade capaz de encontrar soluções para o enfrentamento dos complexos problemas ambientais atuais.

Essa visão holística deve, portanto, situar o contexto histórico-políticosocial em que se estabeleceu um padrão de civilização criado para satisfazer as necessidades de uma sociedade capitalista. Essa relação entre problemática ambiental e nossa sociedade, fundamentada no avanço científico e tecnológico, é corroborada por documentos de política educacional.

No sentido de compreendermos a natureza e a origem da crise ambiental é necessário que façamos um resgate histórico das relações entre Sociedade e Natureza. Milton Santos (2006, p. 156) afirma que "a história das chamadas relações entre sociedade e natureza é a da substituição de um meio natural, dado a uma determinada sociedade, por um meio cada vez mais artificializado". O autor classifica a história do meio geográfico em três períodos: o meio natural, o meio técnico e o meio técnico-científicoinformacional.

Santos (2006, p.158) esclarece que quando o meio geográfico era apenas natural, o ser humano usava técnicas para extrair produtos da natureza utilizados para sua sobrevivência sem, contudo, provocar grandes transformações no ambiente. As necessidades de uso desses produtos surgiam de uma sociedade local, a qual era "criadora das técnicas utilizadas, comandante dos tempos sociais e dos limites de sua utilização". 
O surgimento de artefatos técnicos e do espaço mecanizado - meio técnico - proporcionou ao ser humano a ampliação do processo de produção e, com esse crescimento produtivo, surgiu à necessidade de comercializá-los. De acordo com Santos (2006), o aumento da produção favorecido pela mecanização do meio geográfico começou a produzir os primeiros sinais de desequilíbrio ambiental. De acordo com Lima (2011):

\begin{abstract}
Destacam-se nessa retrospectiva histórica, a Revolução Industrial, inspirada na ideologia do Progresso, com seus desdobramentos; a Empresa Neocolonial, que alimentou o projeto expansionista das nações industriais e as duas grandes guerras mundiais - a última das quais teve como epílogo as explosões nucleares no Japão (p. 116).
\end{abstract}

Contemporaneamente, movidos por interesses capitalistas, os empresários e as multinacionais - denominados por Santos (2006) de atores hegemônicos - investiram na interação entre a técnica e a ciência para obter informações sobre espaço e tempo na busca de ampliar ainda mais a produção e a comercialização de produtos. As técnicas foram sendo cada vez mais aperfeiçoadas pelos conhecimentos científicos que se utilizaram de informações para expandir a produção sobre a proteção do mercado global, caracterizando o que Santos (2006) chama de meio técnico-científicoinformacional.

De posse de informações importantes como o espaço geográfico, condições climáticas e desejos dos consumidores, os atores hegemônicos procuraram especializar territórios de países diferentes na produção de determinados produtos, denominados por Santos (2006, p. 163) de "espaços nacionais da economia internacional". Dessa forma, foi imposto por esse sistema um intercâmbio entre as economias dos países, movido pelos interesses do sistema capitalista, levando as grandes empresas a controlar o mercado global e prevalecer sobre as políticas de governo (SANTOS, 2006).

Nessa conjuntura que busca o crescimento econômico movido por interesses de uma pequena parcela dominante da sociedade surgem os problemas ambientais que, de acordo com Leff (2000, p. 19), são sintomas de uma crise de civilização "marcados pelo transbordamento da economização do mundo guiado pela racionalidade tecnológica e pelo livre mercado". Nesse 
sentido, a crise ambiental emerge num cenário de grandes problemas sociais, entre os quais estão inseridas as perturbações ambientais e ameaças à vida humana, ocasionados pelas mudanças climáticas, pelos diferentes tipos de poluição e pela degradação dos recursos naturais efeitos de um sistema econômico que se consolidou ao longo da história da sociedade contemporânea.

Articulada com a importância de um resgate histórico da relação Sociedade e Natureza, a EA também deve fomentar uma visão pertinente dessa relação, no que se refere às múltiplas contradições e conflitos sociais que ela guarda. Não é possível considerar a relação Sociedade e Natureza, como fazem os ecólogos com as outras espécies vivas, como se a espécie humana fosse uma unidade que se relaciona com o mundo externo natural. Do contrário, a EA deve fomentar a visão de uma sociedade humana diferenciada, conflituosa e que interage com seu entorno a partir de classes sociais e grupos (FOLADORI, 2001). Essa também é uma contribuição fundamental da obra de Karl Marx à Educação Ambiental. Segundo o materialismo histórico, o processo de trabalho envolve duas dimensões: a relação do ser humano com a natureza e a relação dos seres humanos entre si no processo de trabalho. A primeira relação é mediada pela matéria prima e pelos instrumentos de trabalho que, somadas à força de trabalho, constituem as forças produtivas. A segunda relação, ou seja, as interações que os seres humanos estabelecem entre si no processo produtivo, irá determinar as maneiras pelas quais os elementos envolvidos nesse processo serão apropriados e distribuídos.

Nessa perspectiva, articular os problemas ambientais com as desigualdades sociais de várias ordens que caracterizam as relações de produção no capitalismo, torna-se fundamental. No mundo globalizado, as desigualdades entre países levaram ao deslocamento geográfico das fontes de recursos e das áreas de descarte de resíduos. Assim, Lawrence Summers, então economista principal do Banco Mundial em 1992, escrevia que, de um ponto de vista econômico, a contaminação deveria se concentrar nos países pobres (ALIER, 2007). No âmbito das nações, os problemas ambientais atingem diferencialmente os grupos sociais de uma sociedade. Lembre-se que 
o movimento pela justiça ambiental foi organizado contra os casos locais de racismo ambiental nos Estados Unidos. Discrepâncias sociais, no que se refere aos problemas ambientais, também são bastante evidentes em países como 0 Brasil em que o território nacional é coabitado tanto por pessoas que vivem em áreas nobres e valorizadas socialmente quanto por moradores de lixões, ribeirinhos, de encostas, de áreas contaminadas e trabalhadores expostos diariamente à exposição de tóxicos. Ao contrário dos primeiros, as populações mais vulneráveis não possuem a opção de sair dessas situações de risco por falta de condições (LIMA, 2011).

Além da injustiça ambiental, isto é, da imposição desproporcional dos riscos ambientais às populações menos dotadas de recursos financeiros, políticos e informacionais (ASCERALD, 2009), o Brasil também é marcado por conflitos ambientais de diversos tipos. Zhouri e Laschefski (2010) tipificaram esses conflitos em três: os conflitos distributivos, ou seja, aqueles derivados das desigualdades sociais no acesso e na utilização de recursos naturais; os conflitos territoriais, isto é, os conflitos entre grupos sociais portadores de identidades e lógicas culturais diferentes que disputam o mesmo território e os conflitos espaciais, ou seja, aqueles nos quais os efeitos e impactos ambientais ultrapassam os limites entre os territórios.

Além de possibilitar o resgate histórico das relações entre Sociedade e Natureza e uma visão que comporte as contradições e desigualdades contidas nessa relação, a EA deve articular a questão ambiental com o campo de lutas no qual atores sociais diversos, com acessos diferentes aos capitais econômico, cultural, social e simbólico - de uma sociedade, travam uma disputa pela definição dessa própria questão e pela maneira mais legítima de enfrentá-la (BOURDIEU, 2003). Diante da complexidade da crise ambiental, expressa por uma trama de problemas ambientais de ordem social, política, econômica, cultural e natural, emerge o conceito de campo ambiental. Para Carvalho (2008, p.36), campo ambiental é um campo social cuja orientação ética deveria enxergar o meio ambiente como um bem a ser respeitado, admirado e cuidado "para além dos interesses imediatos das sociedades". Segundo a autora: 
O campo ambiental, portanto, busca afirmar-se na esfera das relações conflituosas entre éticas e racionalidades que organizam a vida em sociedade, buscando influir numa certa direção sobre a maneira como a sociedade dispõe da natureza e produz determinadas condições ambientais. Assim, o campo ambiental se constitui necessariamente engajado na disputa pelo poder simbólico de nomear e atribuir sentido ao que seria a conduta humana desejável em um meio ambiente ideal. (CARVALHO, 2008, p. 37)

Dessa forma, o campo ambiental é permeado por lutas e embates entre diferentes grupos que se denominam ambientais buscando por uma hegemonia que oriente a relação sociedade-natureza. Um exemplo dessas disputas é evidenciado por Carvalho (1991). Em sua pesquisa sobre o discurso ambiental brasileiro, Carvalho (1991) afirma que existem duas matrizes discursivas. O primeiro discurso, denominado de discurso ecológico oficial, representado pelo governo e por uma parcela dominante da sociedade, diz que a maioria dos problemas ambientais está relacionada ao subdesenvolvimento e que o "bemestar" será alcançado junto com o desenvolvimento dos países.

Para Carvalho (1991, p. 57), o discurso ecológico oficial "produz uma fala onde clama pela preservação do meio ambiente, comprometido de antemão com as regras do capitalismo industrial". O segundo discurso, chamado de discurso ecológico alternativo, composto pelo movimento social contra hegemônico, contrapõe-se ao primeiro e questiona o modo de vida da sociedade ocidental por meio da crítica radical ao modo de produção industrial impulsionado pelo sistema capitalista. Esse discurso vislumbra um "projeto de sociedade baseado em modos não predatórios de produção, bem como numa outra ética das relações entre os homens" (CARVALHO, 1991, p. 82).

Alonso et al. (2007) também analisaram a formação do movimento ambientalista no Brasil, demonstrando que ele é caraterizado por diferentes frames que irão definir o que é a questão ambiental e as formas de confrontála. Segundo os autores, toda ação coletiva depende das habilidades dos ativistas em construir interpretações acerca da conjuntura em que estão imersos e por meio delas transformar descontentamentos sociais em mobilização. Desse modo: 
Os "frames são esses instrumentos cognitivos e guias para a ação que permitem aos ativistas questionar uma dada situação social antes não problemática, atribuir responsabilidade a grupos ou autoridades por tal estado de coisas e apresentar estratégias para alterá-lo" (Alonso et al, 2007,p. 156).

Alonso et al. (2007) localizam dois frames principais na constituição no movimento ambientalista brasileiro. O frame conservacionista define o meio ambiente como mundo natural e selvagem, a ser preservado da ação detratora de grupos sociais. Esse frame vê qualquer intervenção nesse mundo como uma questão técnica, restrita aos cientistas naturais ${ }^{4}$. Seu discurso é cientificista, pois defende que os especialistas das Ciências Naturais seriam autoridades incontestáveis na definição de problemas e de políticas ambientais. Ademais, no frame conservacionista a questão ambiental encontra-se dissociada das questões sociais. Já para o frame socioambientalista, o mundo urbano deve ser inserido na definição da questão ambiental e as causas da degradação ecológica precisam ser atreladas ao desenvolvimento capitalista e ao estilo de vida moderno. Os autores afirmam que esse frame esteve presente na maior parte das associações ambientalistas surgida nos anos 1970 no Brasil $^{5}$. Seu diferencial é, portanto, associar os problemas ambientais às causas políticas, sociais e econômicas.

Diante do que abordam Carvalho (1991) e Alonso et al. (2007), constatase que, como outros campos sociais, o campo ambiental é marcado por disputas internas no sentido de dominar o universo das relações entre os homens e o ambiente. A conjuntura da formação e fortalecimento do campo ambiental foi marcada por movimentos ambientalistas e também por eventos

\footnotetext{
${ }^{4}$ Alonso et al. (2007) exemplificam esse frame com a Fundação Brasileira para a Conservação da Natureza (FBCN) fundada em 1958, no Rio de Janeiro. Ela foi constituída de engenheiros agrônomos e de cientistas naturais que trabalhavam na burocracia estatal e estavam envolvidos profissionalmente com a questão ambiental.

${ }^{5}$ Exemplos do frame socioambientalista seriam, segundo Alonso et al. (2007), a Associação Gaúcha de Proteção ao Meio Ambiente Natural (AGAPAN) que, para além de profissionais ligados à questão ambiental, atraiu jovens estudantes e se aproximou do movimento pela redemocratização, e o Movimento Arte e Pensamento Ecológico, fundado em São Paulo, 1973, constituído por artistas plásticos, escritores e jornalistas vinculados aos movimentos contraculturais, preocupados com a questão urbana.
} 
internacionais. Refletindo sobre esses últimos, Portilho (2005) demonstra que, da década de 1970 para a década de 1990, ocorreram deslocamentos discursivos importantes nos eventos internacionais sobre a definição da questão ambiental. Do aumento populacional identificado com o hemisfério sul, a questão ambiental passou a ser definida em torno dos modelos de produção do hemisfério norte, na década de 1980, para, na década de 1990, concentrarse no consumo. Com o deslocamento discursivo da produção começaram a ser percebidos como comportamentos e escolhas que afetam a qualidade do meio ambiente.

Portilho (2005) demonstra que o surgimento do "consumidor verde" foi impulsionado pela ambientalização do setor empresarial na década de 1980. Nessa década, tal setor começa a abandonar sua imagem de "vilão da ecologia" e passa a adotar a imagem de "amigo do verde". Se, até então, a ecologia era entendida como um freio ao crescimento econômico e preservar o meio ambiente significava perda de competitividade da empresa frente ao mercado, a partir da década de 1980 os nichos de "mercado verde" passam a ser cada vez mais visados pelo setor empresarial.

O consumidor verde foi definido como aquele que, além da variável qualidade/preço, inclui também a variável ambiental nas suas escolhas de consumo. Como afirma Portilho (2005, p.115), o consumidor é tido como responsável, através de suas demandas e escolhas cotidianas, por gerar mudanças nas matrizes energéticas e tecnológicas do sistema de produção. A pressão exercida pelos consumidores, ao buscarem produtos verdes e boicotarem produtos de grande impacto ambiental impulsionaria, a um só tempo, a competitividade empresarial, o desenvolvimento de produtos ecologicamente corretos e uso de tecnologias limpas. Assim, muitas empresas passaram a se interessar em captar o poder de compra dessas pessoas, com um elevado capital econômico e cultural, percebendo-as como um novo nicho do mercado.

Assim, refletindo a consciência reificada sobre os problemas ambientais, a maioria dos debates sobre a relação entre consumo e meio ambiente deixou 
de lado temas estruturais do capitalismo e começou a enfatizar que a melhoria na qualidade ambiental deveria ser atingida por meio da substituição de bens e serviços por outros mais eficientes e menos poluentes. Tal discurso oblitera que, guiados por interesses particulares, empresários capitalistas buscam descobrir não os bens e consumos de que precisamos em nossa vida, longe disso, eles investem em pesquisas para saber o que nos queremos ter (LEONARD, 2011). Com base nessas informações, as indústrias orientadas por esse modelo de produção e consumo iniciam à produção em larga escala de produtos que satisfaçam as vontades da vida moderna impostas pelo capitalismo. No processo de produção industrial são adicionados tóxicos sintéticos na fabricação de bens para deixá-los duradouros, antiaderentes, resistentes ao fogo, fortes, coloridos, que combatam as pragas entre outras vontades supérfluas estabelecidas pelo capitalismo.

Com o objetivo de inculcar a filosofia do consumismo na população, o capitalismo investe pesado em propagandas veiculadas pela mídia para nos convencer que devemos comprar. Amparado por conceitos como obsolescência planejada simbólica e perceptiva, somos manipulados a consumir produtos que duram cada vez menos e tornam-se obsoletos em um curto espaço de tempo. Essa ideologia traz consequências graves pelo fato de que quanto mais consumimos bens e serviços, estimulamos o aumento da exploração desenfreada dos recursos naturais e aumentamos o processo de produção e descarte de rejeitos oriundos da exploração, fabricação, transporte e comércio desses produtos.

No entanto, o debate sobre os padrões de consumo acabou priorizando propostas sobre mudanças tecnológicas de produtos e serviços, instrumentos econômicos e mudanças nos comportamentos individuais, priorizando uma abordagem tecnicista, economicista e despolitizada (PORTILHO, 2005, p. 110). Nesse sentido, a noção de "consumo verde" torna-se exemplo concreto da reificação da consciência no que se refere ao tratamento da questão ambiental. Tal perspectiva deixaria de focalizar em aspectos, tais como: a redução do consumo, a descartabilidade e a obsolescência programada, enfatizando, por sua vez, as soluções individuais e fragmentadas, tais como: a reciclagem, o 
uso de tecnologias limpas, a redução do desperdício e a propagação de um mercado verde. A possibilidade de escolha estaria resumida à opção entre diferentes marcas, sem que se colocasse em questão o próprio consumismo e o modelo de civilização atual nele calcado (PORTILHO, 2005, p. 126).

\section{CONCLUSÃO}

Este artigo revisitou a noção de reificação, central à crítica marxista ao modo de produção capitalista. A partir daí, procurou-se contribuir para a agenda de construção de uma Educação Ambiental crítica e emancipadora dos agentes sociais. Essa agenda deve conter o compromisso com a construção de uma visão holística e não reducionista da questão ambiental e que abarque as questões sociais, econômicas, políticas e históricas envolvidas na crise do modelo de civilização atual.

Em um primeiro momento, realizamos uma abordagem sobre 0 desenvolvimento do conceito de reificação em Marx e no marxismo ocidental, representado por Lukács. Iniciamos com o tema da alienação, trazido por Marx, nos Manuscritos Econômico-Filosóficos, nos termos de um estranhamento do homem em relação ao produto do seu trabalho. Bastante presente nos Manuscritos, o termo alienação vai sumindo na obra posterior de Marx, certamente, porque este autor queria deixar explícita a distância entre as suas ideias e as da filosofia idealista. Mas, o problema da alienação permanece, pois como Marx (2004, p. 111) afirma a "desvalorização do mundo humano aumenta em proporção direta da valorização do mundo das coisas". Na Ideologia Alemã, a alienação é concebida como fenômeno histórico, calcado na divisão social do trabalho e em $O$ Capital esse problema ressurge na análise do fetichismo da mercadoria.

Nessa última obra, Marx demonstra a forma como a economia política concebe as estruturas do capitalismo, como naturais e eternas, como efeito do fetichismo da mercadoria. Já com o conceito de reificação, Lukács denuncia a expansão do fenômeno da reificação por toda a sociedade, inclusive, abarcando a própria consciência proletária que, contudo, no seu pleno 
desenvolvimento político, é capaz de totalizar a ordem social, ou seja, de compreender as contradições do capitalismo em sua essência.

Sob a reificação e com a fragmentação da experiência social, perde-se a capacidade de ver a sociedade como um processo coletivo e a ordem capitalista torna-se menos vulnerável à crítica. Desse modo, revisitar o conceito de reificação pode nos munir de ferramentas críticas para confrontar propostas e soluções que possuam uma visão redutora dos problemas ambientais e que deixam intacta o questionamento sobre o modelo de civilização no qual vivemos.

Após estabelecer uma abordagem sobre a reificação da realidade social no capitalismo, delineamos que uma Educação Ambiental crítica deve, dentre outros aspectos, fornecer uma contextualização histórico-político-social em que se estabeleceu um padrão de civilização criado para satisfazer as necessidades de uma sociedade capitalista. Como afirma Foladori (2001), diferenças nas formas de produção são decisivas na determinação de que materiais usar, do ritmo com que eles são utilizados e da existência ou não de uma população excedente. Desse modo, as sociedades de caçadores e coletores parecem não apresentar as "necessidades ilimitadas" que os economistas neoclássicos depositam na natureza humana. Essas sociedades subutilizam seus recursos e sua capacidade de trabalho. Os recursos da natureza utilizados são relativamente os mesmos e o seu ritmo de utilização é cíclico. Conclui-se que diferenças nas formas sociais de produção são determinantes do tipo de recurso que se utiliza, da velocidade com que se desenvolve a técnica e do relacionamento com o meio ambiente.

Também destacamos que uma Educação Ambiental de cunho crítico, deve situar a relação Sociedade e Natureza nos conflitos e contradições inerentes às relações de produção sob o capitalismo. Em diversos discursos sobre a questão ambiental é comum identificarmos noções genéricas, tal como a de "humanidade", como se a sociedade como um todo fosse vítima da crescente degradação planetária, não importando a maneira ou onde as pessoas vivem. Nessa concepção, o meio ambiente é percebido como 
naturalmente escasso e os "seres humanos" são vistos como um todo indiferenciado. Sabemos, no entanto, que os riscos ambientais recaem, sobretudo, sobre as populações menos dotadas de recursos financeiros, políticos e informacionais (ASCERALD, 2003).

Em meio a essa complexidade que constitui a questão ambiental, é necessário entender as disputas que constituem o campo ambiental e que visam a definição dos próprios problemas ambientais e da maneira mais legítima de combatê-los. Para Carvalho (2008), a esfera educativa ambiental emerge da intersecção entre o campo ambiental e o campo educativo, originando a Educação Ambiental. Dessa forma, a EA é caracterizada pela incorporação da preocupação ambiental pela educação que a transforma em objeto de teoria e da prática educativa, assim como pelo compartilhamento de identidade entre educadores ambientais que têm "como especificidade o fazer educativo ambiental" (CARVALHO, 2008, p.75).

A Educação Ambiental deve fomentar nos agentes sociais a capacidade de compreender a questão ambiental em toda a sua complexidade, totalizando uma ordem fragmentada que, sob o efeito da reificação, concebe os problemas ambientais deslocados de sua origem e deixa intacto o questionamento sobre 0 modo de civilização em que vivemos. A concepção de EA deve buscar a transformação social que questione o atual modelo de civilização, pautada na articulação dos diversos saberes - científicos e populares - e abranger os múltiplos contextos e atores da sociedade para que os indivíduos possam construir uma visão mais holística da realidade capaz de encontrar soluções para o enfrentamento dos complexos problemas ambientais atuais.

\section{REFERÊNCIAS BIBLIOGRÁFICAS}

ADORNO, T.; HORKHEIMER, M. Dialética do Esclarecimento: fragmentos filosóficos. Tradução de Guido Antonio de Almeida. Rio de Janeiro: Jorge Zahar Ed. 1985.

ALIER, J. M. Correntes do ecologismo. O ecologismo dos pobres: conflitos ambientais e linguagens de valoração. São Paulo: Contexto. 2007. 
ALONSO, A.; COSTA, V.; MACIEL, D. "Identidade e estratégia na formação do movimento ambientalista brasileiro”. Novos estudos - CEBRAP, São Paulo, n. 79, p. 151-167. Nov. 2007

ANDERSON, P. Considerações sobre o marxismo ocidental \& Nas trilhas do materialismo histórico. São Paulo: Boitempo. 2004.

ASCERALD, H. O que é justiça ambiental ? Rio de Janeiro: Garamond. 2009.

BOURDIEU, P. Questões de sociologia. Lisboa: Fim de século. 2003.

BUTTEL, F. "A Sociologia e o Meio Ambiente: um caminho tortuoso rumo à ecologia humana". Perspectiva: Revista de Ciências Sociais. São Paulo. Unesp. v. 15. p. 69-94. 1992.

CARVALHO, I. C. M. Territorialidades em luta: uma análise dos discursos ecológicos. São Paulo: Instituto Florestal, 1991.

CARVALHO, I. C. M. Educação Ambiental: a formação do sujeito ecológico. São Paulo: Cortez. 2008.

FAUSTO, R. Marx: Lógica e Política. São Paulo: Brasiliense. 1987.

FOLADORI, G. Limites do Desenvolvimento Sustentável, Campinas: Editora Unicamp. 2001.

EAGLETON, T. Ideologia. São Paulo: Boitempo. 1997.

LAYRARGUES, P. P. O cinismo da reciclagem: o significado ideológico da lata de alumínio e suas implicações para a educação ambiental. In: LOUREIRO, F.; LAYRARGUES, P.; CASTRO, R. (Org.) Educação ambiental: repensando o espaço da cidadania. São Paulo: Cortês, 2011.

LEFF, E. Complexidade, interdisciplinaridade e saber ambiental. In: PHILIPPI JÚNIOR, R. A. (Org.). Interdisciplinaridade em ciências ambientais. São Paulo: Signus, 2000.

LEONARD, A. A história das coisas: da natureza ao lixo, o que acontece com tudo o que consumimos. Rio de Janeiro: Zahar, 2011.

LIMA, G. F. C. Crise ambiental, educação e cidadania: desafios da sustentabilidade emancipatória. In: LOUREIRO, F.; LAYRARGUES, P.; CASTRO, R. (Org.) Educação ambiental: repensando o espaço da cidadania. São Paulo: Cortês, 2011

LOUREIRO, C. F. "Complexidade e dialética: contribuições à práxis política e emancipatória em educação ambiental”. Educação e Sociedade, Campinas, v. 26, n. 93, p. 131-152, set./dez. 2005. 
LUKÁCS, G. História e Consciência de Classe: estudos sobre a dialética marxista. São Paulo: Martins Fontes. 2003.

MARX, K. O Capital: Crítica da Economia Política. Rio de Janeiro: Civilização Brasileira. 1999.

. Manuscritos Econômico-Filosóficos. São Paulo: Martin Claret. 2004.

. A Ideologia Alemã. São Paulo: Martin Claret. 2008.

MÉZÁROS, I. A Teoria da Alienação em Marx. São Paulo: Boitempo. 2006.

PORTILHO, F. Sustentabilidade ambiental, consumo e cidadania. São Paulo: Cortez, 2005.

RICOUER, P. L’Idéologie et l'utopie, Paris: Éditions du Seuil. 1997.

SANTOS, M. A natureza do espaço. São Paulo : Editora Hucitec. 2006.

ZHOURI, A.; LASCHEFSKI, K.. Introdução. In: Zhouri, A.; Laschefski, K. (org.). Desenvolvimento e conflitos ambientais: Um Novo Campo de Investigação. Belo Horizonte: Editora UFMG. 2010. 